\title{
In-situ observations of aerosol particles remaining from evaporated cirrus crystals: Comparing clean and polluted air masses
}

\author{
M. Seifert ${ }^{1,2}$, J. Ström ${ }^{2}$, R. Krejci ${ }^{1,2}$, A. Minikin ${ }^{3}$, A. Petzold ${ }^{3}$, J.-F. Gayet ${ }^{4}$, U. Schumann ${ }^{3}$, and J. Ovarlez ${ }^{5}$ \\ ${ }^{1}$ Department of Meteorology, Stockholm University, Stockholm, Sweden \\ ${ }^{2}$ Air Pollution Laboratory, Institute for Applied Environmental Research, Stockholm University, Stockholm, Sweden \\ ${ }^{3}$ Deutsches Zentrum für Luft- und Raumfahrt, Institut fr Physik der Atmosphäre, Oberpfaffenhofen, Germany \\ ${ }^{4}$ Laboratoire de Météorologie Physique, Université Blaise Pascal, Clermont-Ferrand, France \\ ${ }^{5}$ Laboratoire de Météorologie Dynamique, Ecole Polytechnique, Palaiseau, France
}

Received: 3 July 2002 - Published in Atmos. Chem. Phys. Discuss.: 19 October 2002

Revised: 3 March 2003 - Accepted: 4 April 2003 - Published: 16 July 2003

\begin{abstract}
In-situ observations of aerosol particles contained in cirrus crystals are presented and compared to interstitial aerosol size distributions (non-activated particles in between the cirrus crystals). The observations were conducted in cirrus clouds in the Southern and Northern Hemisphere midlatitudes during the INCA project. The first campaign in March and April 2000 was performed from Punta Arenas, Chile $\left(54^{\circ} \mathrm{S}\right)$ in pristine air. The second campaign in September and October 2000 was performed from Prestwick, Scotland $\left(53^{\circ} \mathrm{N}\right)$ in the vicinity of the North Atlantic flight corridor. Size distribution measurements of crystal residuals (particles remaining after evaporation of the crystals) show that small aerosol particles $\left(D_{p}<0.1 \mu \mathrm{m}\right)$ dominate the number density of residuals. The crystal residual size distributions were significantly different in the two campaigns. On average the residual size distributions were shifted towards larger sizes in the Southern Hemisphere. For a given integral residual number density, the calculated particle volume was on average three times larger in the Southern Hemisphere. This may be of significance to the vertical redistribution of aerosol mass by clouds in the tropopause region. In both campaigns the mean residual size increased slightly with increasing crystal number density. The form of the residual size distribution did not depend on temperature as one might have expected considering different modes of nucleation. The observations of ambient aerosol particles were consistent with the expected higher pollution level in the Northern Hemisphere. The fraction of residual particles only contributes to approximately a percent or less of the total number of particles, which is the sum of the residual and interstitial particles. Excellent agreement between the CVI and FSSP-300 probes was found supporting the assumption that each crystal is associated with only one residual particle.
\end{abstract}

Correspondence to: M. Seifert (marco.seifert@itm.su.se)

\section{Introduction}

The indirect effect of anthropogenic aerosol and in particular its potential impact on cirrus clouds is rated one of the most uncertain components of climate forcing (IPCC, 1999). While at least some insight is available about the aerosol-cloud interaction of warm clouds, where anthropogenic aerosol particles may increase the cloud droplet concentrations, the aerosol-cloud interaction of cold cirrus clouds is still not very well understood (Baker, 1997).

The formation of ice crystals in the atmosphere depends strongly on temperature, relative humidity and updraft velocity (Kärcher and Lohmann, 2001). Very little is actually known about the aerosol that participates in cirrus formation and whether nucleation is predominately homogeneous or heterogeneous. Only isolated in-situ studies of the nature of aerosol particles involved in cirrus formation exist. Noone et al. (1993) and Ström et al. (1997) presented the first size distributions of residual particles indicating the importance of submicron aerosol particles for cirrus formation. Single particle analyses of elemental composition of residual particles by Heintzenberg et al. (1996) and Twohy and Gandrud (1998) showed that particles larger than a few hundred nanometers in diameter predominantly contain mineral elements. Near flight corridors the contribution of soot particles is enhanced (Petzold et al., 1999).

Airborne measurements with an ice nucleus (IN) counter (Rogers et al., 1998) showed that the IN concentration strongly related to sampling temperature and supersaturation level. The number concentration of condensation nuclei $(\mathrm{CN})$ and IN did not generally correlate, suggesting different source regions for these populations of particles.

This study presents the largest data set presently available of in-situ observations of concurrent or close to concurrent measurements of interstitial aerosol and cloud residual size distributions. To the authors knowledge this is also the first 
time that this type of data has been obtained for both the Southern and Northern Hemisphere mid-latitudes, which allows to compare and contrast the two regions. The observations were performed during two campaigns within the project INCA (Interhemispheric differences in cirrus properties from anthropogenic emissions). The main objective of this project is to contrast cirrus observations made in a pristine environment to those performed in an environment strongly affected by anthropogenic emissions. The analysis will focus on the similarities and differences of the particles found in cirrus crystals observed in the two campaigns.

\section{Experimental}

Data was collected during two aircraft campaigns, one in the Northern Hemisphere (NH) and one in the Southern Hemisphere (SH). Both campaigns took place at similar latitude as well as in equivalent seasons, within the same year. The first campaign (10 flights) in March/April 2000 was performed from Punta Arenas, Chile $\left(54^{\circ} \mathrm{S}\right)$ in pristine air. The mission flights were mainly flown west of Punta Arenas. During the second campaign in September/October 2000 nine measurement flights were performed from Prestwick, Scotland $\left(53^{\circ} \mathrm{N}\right)$. The observations were made mainly north of Prestwick in the vicinity of the North Atlantic flight corridor.

\subsection{Instrumentation}

The in-situ observations were performed using the identical payload in both experiments. The equipment was mounted onboard the research aircraft Falcon, operated by the Deutsches Zentrum fr Luft- und Raumfahrt. The Falcon instrumentation for meteorological data was used to provide atmospheric state parameters and aircraft position. Several different sample techniques were used to study cloud microphysical properties, residual particles and cloud water remaining from evaporated crystals as well as non-activated (interstitial) aerosol particles in cirrus clouds (Table 1).

\subsubsection{Cloud microphysical properties}

The Polar Nephelometer, a unique airborne in situ probe, measures the scattering phase function of cloud particles with help of a collimated laser beam. With the direct measurement of the scattering phase function cloud optical parameters could be calculated, and it was possible to distinguish between water droplets and ice particles. For further details on this probe we refer to Gayet et al. (2002).

The FSSP-300 measures the number density of cirrus crystals in 31 size classes in the nominal size range 0.3 to $20 \mu \mathrm{m}$ according to the specification of the manufacturer. Crystals entering the FSSP probe are illuminated by a laser beam, and the scattered light is inverted to particle size (Baumgardner et al., 1992). Because the ice crystals are not spherical a FSSP-300 size calibration for aspherical particles proposed by Borrmann et al. (2000) was used in this study. Borrmann et al. (2000) calculate size bin limits for a refractive index of 1.33 using the T-matrix method. Application of this calibration in cirrus clouds results in 29 size classes measured by the FSSP-300 in the size range 0.38 to $15.8 \mu \mathrm{m}$. The integral crystal number density given by this instrument will be referred to as $\mathrm{N}_{\mathrm{FSSP}}$. Due to noise the first three channels were not used.

\subsubsection{Residual particles and crystal water properties}

The CVI is a device that inertially separates crystals larger than about $5 \mu \mathrm{m}$ and smaller than about $60 \mu \mathrm{m}$ (aerodynamic size) from the surrounding air into a warm, dry and particlefree air flow (Ström et al., 1997; Noone et al., 1988). Different sensors working down stream of the CVI-inlet measured water vapor and "dry" non-volatile residues (at $25-30^{\circ} \mathrm{C}$ ) left behind by the evaporated crystals. The residues will be referred to as residual particles. Due to the design of the CVI probe the sampled air is enriched compared to ambient conditions. During the two campaigns the enrichment factor was typically around 150 . All measured parameters have therefore been calculated back to ambient conditions.

The water vapor from the evaporated cloud elements was measured by a dual-beam Lyman- $\alpha$ hygrometer (Zuber et al., 1987). From this measurement we can calculate the ice water content (IWC) in cloud particles for crystals in the sampling size range of the CVI probe. The residual particles were characterized with respect to number and size. The number density of residual particles larger than $0.01 \mu \mathrm{m}$ in diameter $\mathrm{N}_{\mathrm{CVI}}, 10$ was measured using a TSI-3010 condensation particle counter (CPC).

A PMS PCASP (Passive Cavity Aerosol Spectrometer) was operated to determine the residual number size distribution in the diameter size range $0.12-3.5 \mu \mathrm{m}$. The instrument uses the scattering properties of aerosol particles to classify them into 32 size bins. The first two channels of the instrument showed not to be reliable during this experiment, and have therefore been excluded from the data interpretation. The integral value of the remaining channels, particles with a diameter larger than $0.12 \mu \mathrm{m}$, will be referred to as the accumulation mode residual particle concentration $\mathrm{N}_{\mathrm{CVI}, 120 \text {. }}$

In addition a custom built Differential Mobility Analyzer (DMA) connected to a second TSI 3010 CPC was operated to derive the residual size distribution below the detection limit of the PCASP. The instrument selects particles in a narrow size range according to their mobility in an electric field and determines their number density. Ten mobility bins were scanned within a time period of one minute. The mobility bins were chosen to be multiples, with the restriction that the highest mobility (or lowest diameter) bin corresponds to $D_{p}=0.025 \mu \mathrm{m}$. Since aerosol mobility depends not only on particle size and number of adhered charges, but on pressure as well, the particle sizes corresponding to a particular mobility will change with altitude. Hence the largest size bin 
Table 1. INCA aircraft payload

\begin{tabular}{llcc}
\hline Instrument & Measurement & Range & Inlet \\
& Cloud microphysical properties & & \\
\hline $\begin{array}{l}\text { Polar Nephelometer } \\
\text { PMS-FSSP-300 }\end{array}$ & Scattering phase function & $1-500 \mu \mathrm{m}$ & Wing mount \\
& Crystal size distribution & $0.3-20 \mu \mathrm{m}$ & Wing mount \\
\hline TSI 3010 CPC & Residual particles and crystal water properties & & \\
DMA & Residual number density & $>0.01 \mu \mathrm{m}$ & CVI-probe \\
PMS-PCASP & Residual size distribution & $0.025-0.1 \mu \mathrm{m}$ & CVI-probe \\
Lyman- $\alpha$ hygrometer & Residual size distribution & $0.12-3.5 \mu \mathrm{m}$ & CVI-probe \\
& Cloud water content & $0.1-30 \mathrm{mg} / \mathrm{kg}$ & CVI-probe \\
\hline TSI 3010 CPC & Interstitial aerosol properties & & \\
DMA & Aerosol number density & $>0.005 \mu \mathrm{m}$ & Aerosol probe \\
PMS-PCASP & Aerosol size distribution & $0.025-0.1 \mu \mathrm{m}$ & Aerosol probe \\
& Aerosol size distribution & $0.15-0.94 \mu \mathrm{m}$ & Wing mount \\
\hline
\end{tabular}

(smallest mobility) varies between 0.149 and $0.155 \mu \mathrm{m}$ for different altitude levels. With an inversion routine we can derive from this mobility measurement the size distribution of the crystal residuals. However, in order to apply the inversion to the data we need to know the contribution of doubly charged particles from particle sizes larger than the upper size limit of the DMA. Normally, this information was obtained by concurrent PCASP measurements. However, this is not practical as we can only derive a DMA size distribution when PCASP data is available. Instead we approximate the impact of doubly charged particles from PCASP size particles based on the average PCASP size distributions. Due to the shape of the distribution (decreasing number density with increasing size) the double charge correction is very small for particles below $0.1 \mu \mathrm{m}$ and the resulting uncertainty from this procedure is negligible. We therefore exclude the two lowest mobility bins $\left(\mathrm{D}_{\mathrm{p}}>0.1 \mu \mathrm{m}\right)$ from the analysis. With the remaining eight size bins we interpolate nine logarithmic equidistant size classes ranging between $0.025-0.1 \mu \mathrm{m}$ in diameter.

Combining the CPC, DMA and PCASP measurements yields a composite residual size distribution for particles with a diameter between $0.01-3.5 \mu \mathrm{m}$.

\subsubsection{Interstitial/ambient aerosol properties}

In conjunction with the CVI measurements the interstitial (non-activated particles left in between the cloud elements) or out-of-cloud (ambient) aerosol was measured with an almost identical set up as for the measurement of the crystal residuals. Two complementary sampling methods were used. The accumulation mode aerosol was measured by a PMS PCASP wing mounted probe $(0.15-0.94 \mu \mathrm{m})$. This instrument is a wing-mounted version of the PCASP used inside the aircraft. The aerosol is dried prior to detection $(\mathrm{RH}<$ $10 \%$ ) with a custom-built sheath flow device and therefore the measured size distribution is referred to as a "dry" size distribution. In addition a plate in front of the inlet deflects crystals from the sample air. Since the first channel of the wing mounted instrument showed not to be reliable during this experiment it was not included in the data interpretation.

Besides the wing probe we used two aerosol inlets of the same type to sample the ambient/interstitial aerosol. These simply consist of 1/4 inch stainless steel tubes turned opposite to the flight direction. Large particles pass by the probes because of their inertia (Schröder and Ström, 1997) causing particles larger than about $1 \mu \mathrm{m}$ in diameter not to be sampled. The interstitial particle size distribution between 0.025 and $0.1 \mu \mathrm{m}$ was derived with a second DMA set-up identical to the one described for the crystal residual particles. Several types of CPCs where used to measure the total number density of interstitial and out-of-cloud aerosol. In this study we make use of a modified version of the TSI 3010 CPC, which measures the number density of particles larger than $0.005 \mu \mathrm{m}$ in size $\mathrm{N}_{\text {int, } 5}$.

Combining the measurements by CPC, DMA and PCASP we obtain a composite particle size distribution $\left(D_{p}=0.005-\right.$ $0.94 \mu \mathrm{m}$ ) for the interstitial/ambient aerosol particles.

\section{Results}

We limit our data set to cirrus measurements at temperatures below $-30^{\circ} \mathrm{C}$, when cloud elements almost certainly are frozen. The few occasions, when liquid water clouds were detected by the Polar Nephelometer at temperatures down to $-34^{\circ} \mathrm{C}$, were excluded from the data set. Furthermore, we exclude stratospheric cirrus observations, as they only account for some minutes of the total measurement time. To differentiate between troposphere and stratosphere we used the vertical distribution of ambient aerosol particles and the temperature profiles. In addition we restrict our data analysis 


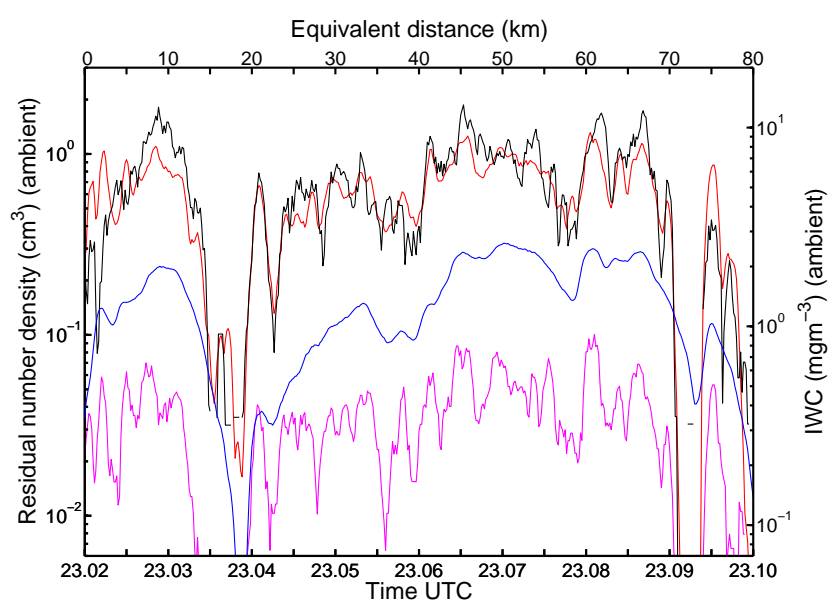

Fig. 1. Example of time series obtained during the INCA SHcampaign on 6 April 2000. Plotted microphysical parameters: crystal concentration ( $\mathrm{N}_{\mathrm{FSSP}}$, black line), the CVI residual number density ( $\mathrm{N}_{\mathrm{CVI}, 10}$, red line; $\mathrm{N}_{\mathrm{CVI}, 120}$, magenta line), the ice water content from the CVI (IWC, blue line). Data gaps for the IWC corresponds to time periods when the hygrometer was saturated. A lower size limit of $6 \mu \mathrm{m}$ was chosen for the FSSP-300 data since it gave the best agreement $\mathrm{N}_{\mathrm{FSSP}}$ and $\mathrm{N}_{\mathrm{CVI}, 10}$. Data presented as $5 \mathrm{~s}$ moving averages.

to observations made in the upper troposphere above $6 \mathrm{~km}$. Finally, our analysis of the data has shown that poor counting statistic makes it difficult to interpret size distribution measurements for low residual number densities. A minimum integral residual number density of $0.1 \mathrm{~cm}^{-3}$ yields an acceptable statistical sample even for larger particles. More on this issue below where we test the significance of our observed size distributions. After this data reduction, the remaining observations correspond to more than 6 and 9 hours of in-cloud data at $\mathrm{N}_{\mathrm{CVI}}, 10>0.1 \mathrm{~cm}^{-3}$ for the Southern and Northern hemisphere, respectively.

The analysis will result in size distribution and number density data being presented as different means and ratios derived for the Southern and Northern Hemisphere campaigns. The key premise when interpreting residual particle observations made by the CVI is the assumption of a one-to-one relation between residual particles and cirrus crystals. To show the validity of this assumption and to introduce the data, we present in Fig. 1 a 10 min time segment of CVI and FSSP data from a flight conducted during the SH-campaign.

\subsection{Consistency of measurements}

On the evening of 6 April a measurement flight was performed that started at 20:56 UTC (16:56 local time), which was approximately $1.5 \mathrm{~h}$ before sunset. The satellite image showed a cirrus cloud-band associated with a frontal system extending roughly from northwest to southeast and approaching Punta Arenas from the west. After take-off the aircraft headed southwest in order to reach a point which was expected to be well behind the cloud band at $80^{\circ} \mathrm{W}$ and $60^{\circ} \mathrm{S}$. Flying $30 \mathrm{~min}$ in clear sky the cirrus field was reached and entered from above at $8800 \mathrm{~m}$ altitude. The descent into the cirrus cloud continued down to $7600 \mathrm{~m}$ where the cirrus was still visible from the aircraft. The aircraft continued approximately $20 \mathrm{~min}$ at this flight level when the edge of the cloud field was reached.

Figure 1 presents a time series of microphysical parameters obtained during the first $10 \mathrm{~min}$ of this flight leg (altitude $7600 \mathrm{~m}$ ). The observed temperature was around $-37^{\circ} \mathrm{C}$. The plotted parameters are: $\mathrm{N}_{\mathrm{FSSP}}$, IWC, $\mathrm{N}_{\mathrm{CVI}}, 10$ and $\mathrm{N}_{\mathrm{CVI}}, 120$. The $\mathrm{N}_{\mathrm{FSSP}}$ is the integral crystal number density for particle diameters larger than a size interpreted as $6 \mu \mathrm{m}$ by the instrument. This size was chosen, since it gave the best agreement between $\mathrm{N}_{\mathrm{FSSP}}$ and $\mathrm{N}_{\mathrm{CVI}}$,10 for this particular flight segment. Note that the CVI selects particles based on the aerodynamic properties of the crystal whereas the FSSP-300 inverts the scattered light from a particle based on assumed optical properties of the crystal. The data is presented as $5 \mathrm{~s}$ moving averages. Figure 1 highlights the consistency of the instruments even for rather small-scale features. The different parameters correlate extremely well yet based on totally different physical principles of the CVI and the FSSP-300. Note that the IWC presented in Fig. 1 is a direct measurement of cloud water and not a derived quantity, thus it is an independent measurement.

The performance of the CVI and the FSSP probes in cirrus has been under scrutiny for some time and there has been a concern that reports of numerous small crystals in cirrus clouds (e.g. Ström et al., 1994; Arnott et al., 1994) would be caused by sampling artifacts, such as crystal break-up or multiple residuals in crystals. Gayet et al. (2002) presented an analysis were cloud probes used during the INCA experiment were compared. Besides the CVI and FSSP-300 probes, this analysis also included the PMS-2D-C probe and the Polar Nephelometer. The study shows a very good agreement between the different probes and the fact that the entire crystal size distribution (FSSP-300 and PMS-2D-C) must be considered in order to explain the extinction coefficient observed by the Polar Nephelometer. Since the observations presented in Fig. 1 correlate over several orders of magnitude in crystal number density and over the entire flight segment, any sampling problem in the two probes must be present at all times and scale the same over the entire measurement domain, despite the different physical measurement principles.

We extend the study by Gayet et al. (2002) by presenting Fig. 2, which shows a comparison between the FSSP-300 and the CVI for the entire INCA project. The comparison includes more than 20 hours of in-cloud observations from two different campaigns (Punta Arenas and Prestwick). A lower limit of $4 \mu \mathrm{m}$ for the FSSP-300 data has shown to give the best agreement between $\mathrm{N}_{\mathrm{FSSP}}$ and $\mathrm{N}_{\mathrm{CVI}}, 10$ when considering the entire data set. The resulting data has been classified according to $\mathrm{N}_{\mathrm{CVI}}, 10$ into bins. Then average/median FSSP-300 concentration and the 10th and 90th percentiles 


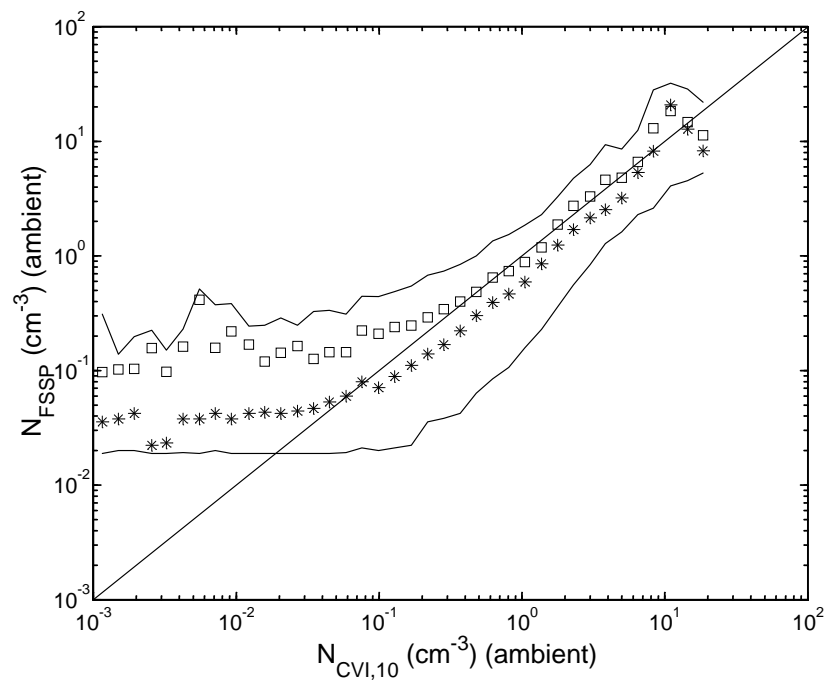

Fig. 2. Comparison of the ice particle concentration obtained from the CVI and the FSSP-300. A lower size limit of $4 \mu \mathrm{m}$ was chosen for the FSSP-300 data since it gave the best agreement $\mathrm{N}_{\mathrm{FSSP}}$ and $\mathrm{N}_{\mathrm{CVI}}$,10. Averages shown as open squares and medians as stars. The two thin lines correspond to the 10th and 90th percentiles. The dash-dotted line illustrates a 1:1 relation between $\mathrm{N}_{\mathrm{FSSP}}$ and $\mathrm{N}_{\mathrm{CVI}, 10}$.

were calculated for each $\mathrm{N}_{\mathrm{CVI}}, 10$ bin. Figure 2 shows a very good agreement between $\mathrm{N}_{\mathrm{FSSP}}$ and $\mathrm{N}_{\mathrm{CVI}}, 10$ at crystal number densities between 0.1 and $5 \mathrm{~cm}^{-3}$ for average and median data. At lower number densities $\mathrm{N}_{\mathrm{FSSP}}$ is nearly constant which is due to the fact that a $10 \mathrm{~s}$ averaging time one crystal count by the FSSP-300 corresponds to an ambient concentration of $0.1 \mathrm{~cm}^{-3}$. Note that the number of observations decreases dramatically above $5 \mathrm{~cm}^{-3}$, hence the data in this concentration range corresponds only to few atmospheric situations. Figure 2 shows also a linear curve, illustrating a one-to-one relation between $\mathrm{N}_{\mathrm{FSSP}}$ and $\mathrm{N}_{\mathrm{CVI}}$,10. Ideally, our data should be distributed on top of this curve. However, the average data tends to give higher values for $\mathrm{N}_{\mathrm{FSSP}}$ whereas the median data tends to give lower values for $\mathrm{N}_{\mathrm{FSSP}}$. Obviously, the exact relation between $\mathrm{N}_{\mathrm{FSSP}}$ and $\mathrm{N}_{\mathrm{CVI}}, 10$ depends on if we are using average or median as well as on the chosen lower limit for the FSSP-300 data. At number densities above approximately $1 \mathrm{~cm}^{-3}$ the definition of crystal size by the two instruments becomes important. Because the crystal size distribution often is very steep at small sizes when the integral number density is high, an uncertainty of $\pm 1 \mu \mathrm{m}$ in the aerodynamic cut-off by the CVI and the size interpreted by the FSSP-300 may cause an offset in the crystal integral number density between the two instruments. The broadening of the percentiles towards lower $\mathrm{N}_{\mathrm{CVI}}, 10$ can be explained by counting statistics alone. This excellent agreement between the CVI and the FSSP-300 gives us confidence that the two instruments work well in cirrus clouds and that the one-toone relation between cirrus crystals and residual particles is valid.

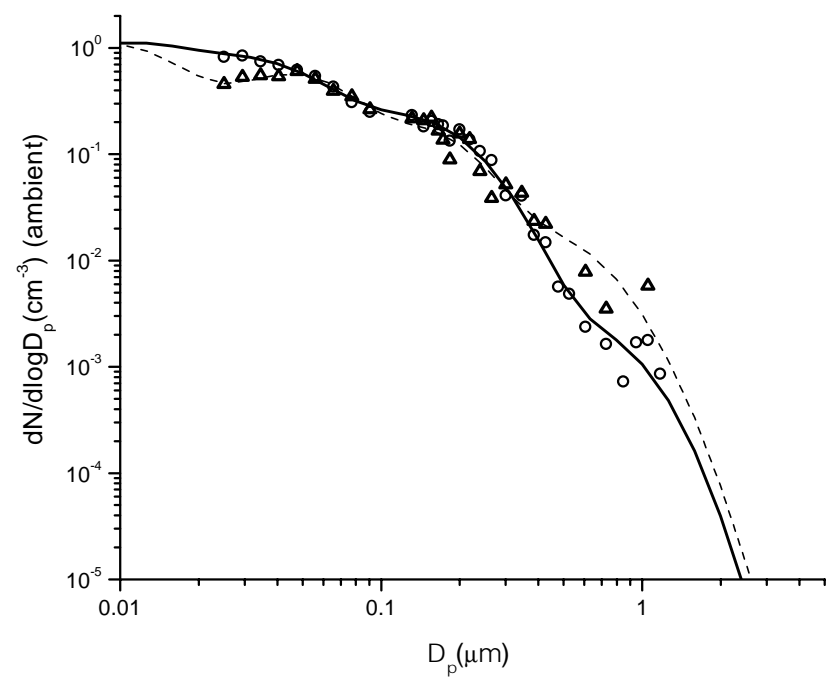

Fig. 3. Measurement of the residual size distribution for the flight segment presented in Fig. 1. The open triangles correspond to a single residual size distribution obtained during a 60 s time segment marked with horizontal bars in Fig. 1. The open circles show the average residual size distribution for the in Fig. 1 presented entire flight segment. For comparison both distributions have been normalized to an integral number density of $1 \mathrm{~cm}^{-3}$. The lines represent the sum of lognormal distributions, fitted to match the corresponding $\mathrm{N}_{\mathrm{CVI}}, 10$ values.

The strong correlation between $\mathrm{N}_{\mathrm{CVI}}, 10$ and $\mathrm{N}_{\mathrm{CVI}, 120}$ suggests further that there are only small changes in the shape of the residual size distribution during the flight segment presented in Fig. 1. The large difference between the two integral numbers also indicates that particles larger than $0.12 \mu \mathrm{m}$ in diameter only contribute to a small fraction of the total number of residuals. This is also confirmed by the DMA measurements, as we will see below.

However, when interpreting the DMA measurements one has to keep in mind that it requires $60 \mathrm{~s}$ to scan through one size distribution. At a typical cruising speed of around $175 \mathrm{~ms}^{-1}$, one scan corresponds therefore to a distance of more than $10 \mathrm{~km}$. Obviously the cloud may change during one size scan. Before details of our measurements will be hidden in statistic we will have a closer look at a single size distribution and the residual size distribution derived for the entire flight segment (Fig. 3). The single scan presented in Fig. 3 is taken from a section of the cloud where there was relatively little cloud variability and a fairly high crystal number density $\left(\mathrm{N}_{\mathrm{CVI}}, 100.73-1.25 \mathrm{~cm}^{-3}\right)$. This period is indicated with horizontal bars in Fig. 1. The concurrent measurements by the PCASP coupled to the CVI are also included into Fig. 3. For comparison the size distribution data for the single scan and the flight segment is normalized to $1 \mathrm{~cm}^{-3}$ in order to study the shape rather than the amplitude of the distributions. The fits to the data, to guide the eye, are based on the sum of lognormal distributions. Above 
approximately a diameter of $1 \mu \mathrm{m}$ the lines in Fig. 2 are simply extrapolations. The mode for particle diameters smaller than $0.025 \mu \mathrm{m}$ is constrained by the shape of the distribution in the Aitken mode, and the difference between the $\mathrm{N}_{\mathrm{CVI}, 10}$ and the integral number of particles larger than $0.025 \mu \mathrm{m}$ in diameter (DMA integral).

Despite the different physical principle of size measurements, electrical mobility for the DMA and optical property for the PCASP, the two instruments show good consistency for sizes around $0.1 \mu \mathrm{m}$ where the size ranges of the two instruments merge. At sizes larger than about $0.4 \mu \mathrm{m}$ we note that the PCASP data suffers from poor counting statistic and that some bins did not register a single count during the $60 \mathrm{~s}$ average.

Next, the single scan is compared to the flight leg average. As expected from the persistent relation between $\mathrm{N}_{\mathrm{CVI}, 10}$ and $\mathrm{N}_{\mathrm{CVI}, 120}$ data in Fig. 1, the two distributions in Fig. 3 resemble each other quite well. The flight segment average presents less scattering and the size distribution is better determined in the large particle range. Although, accumulation sized particles do not contribute significantly to the number of residuals, they are important in terms of aerosol volume or mass.

It would be advantageous to analyze the size distributions at high time resolution corresponding to small spatial extents, but from the data presented above we see that we have to make compromises with respect to resolution and counting statistics. For a given sampling period the DMA measurements may be affected by cloud variability and the PCASP measurements may suffer from counting statistic. We therefore like to view our size bins as independent variables and study them as a statistical ensemble. However, this is not entirely true since corrections for double charges are based on the number density in neighboring size bins. Fortunately, the double charge corrections are small or negligible in the size range of the DMA used in this experiment. From the one minute- and flight segment average size distribution presented in Fig. 3, we proceed by presenting campaign averages.

\subsection{Statistics over all mission flights}

\subsubsection{Campaign averages}

In Fig. 4 the average residual particle size distributions from the Northern and Southern Hemisphere campaigns are presented. The data has been visually fitted by the sum of logarithmic distributions. As in Fig. 3 the mode for particle diameters smaller than $0.025 \mu \mathrm{m}$ is constrained by the shape of the distribution in the Aitken mode, and the difference between the $\mathrm{N}_{\mathrm{CVI}, 10}$ and the DMA integral number density. Note that all the following size distribution data is fitted in the same way. The case study in the previous section indicated that particles in the PCASP range contribute only to a small fraction of residual particles. Plotting the measured residual
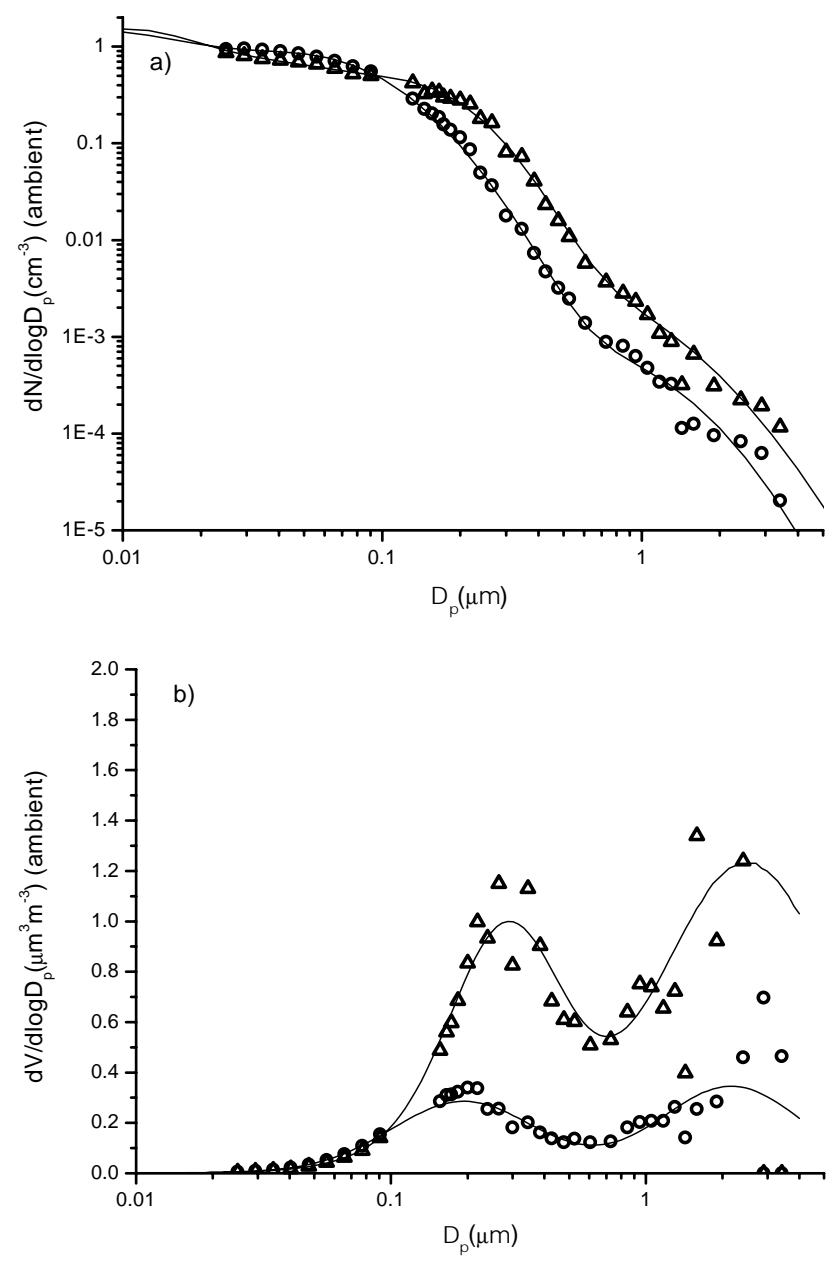

Fig. 4. Residual size distributions as campaign averages shown as open triangles for the $\mathrm{SH}$, respectively open circles for the NH. For comparison the data has been normalized to an integral number density of $1 \mathrm{~cm}^{-3}$. The solid lines represent the sum of lognormal distributions, fitted to match the corresponding campaign averages of $\mathrm{N}_{\mathrm{CVI}, 10}$. (a) Residual size distributions presented as number versus diameter. (b) Residual size distributions presented as volume versus diameter.

number distributions as campaign averages reveals that this observation is consistent with the entire experiment (Fig. 4a). For comparison the distributions are normalized to an integral number density of $1 \mathrm{~cm}^{-3}$. The number density of residuals is dominated by particles smaller than $0.1 \mu \mathrm{m}$ in diameter (approximately $90 \%$ and $95 \%$ of the residual particles by number in the $\mathrm{SH}$ and $\mathrm{NH}$, respectively). The two distributions are fairly similar, but the SH-distribution is shifted towards larger particle sizes. The statistical significance of this observed difference was shown by a two-tailed t-test. In the size range 0.025 to $0.1 \mu \mathrm{m}$ the confidence level was greater than $95 \%$ with exception of the largest and smallest DMA bin, where the confidence level was approximately $70 \%$. For particles larger than $0.1 \mu \mathrm{m}$ in diameter the confidence level 
was better than $99.9 \%$. The importance of this shift in size distribution is highlighted when the normalized data is plotted as a volume distribution in Fig. 4b.

Figure $4 \mathrm{~b}$ shows that practically all the volume of the residual particles is located at sizes above $0.1 \mu \mathrm{m}$. Hence, significantly more aerosol volume is incorporated in each cirrus crystal in the $\mathrm{SH}$ compared to the $\mathrm{NH}$ for same number density. We also note in Fig. 4b that the volume distributions are not simply a difference in amplitude. The left most mode is located at about $0.3 \mu \mathrm{m}$ for the SH data compared to about $0.2 \mu \mathrm{m}$ for the $\mathrm{NH}$ data. The scatter in the data above $1.5 \mu \mathrm{m}$ makes it difficult to say something about differences in the right hand modes. The uncertainty in the measured particle number concentration depends on counting statistics and is equal to the square root of the number of particles counted per sampling period (the whole campaign in this case). Hence, the uncertainty decreases with increasing residual number density and averaging time. For the DMA data $\left(D_{p}=0.025-0.1 \mu \mathrm{m}\right)$ the uncertainty is less then $0.1 \%$. In the PCASP size range the counting statistic uncertainty increases strongly with particle size. For particles between 0.1 and $1 \mu \mathrm{m}$ the uncertainty is less than $2 \%$ and $1.5 \%$ for the $\mathrm{NH}$ and $\mathrm{SH}$, respectively. For particles larger than $1 \mu \mathrm{m}$ the uncertainty is essentially a function of size. The uncertainty increases from 2 to $10 \%(\mathrm{NH})$ and 1.5 to $5 \%(\mathrm{SH})$ when changing the particle diameter from 1 to $3.5 \mu \mathrm{m}$.

Integrating the fitted volume distributions up to $1.5 \mu \mathrm{m}$ (up to the size where the scatter is still fairly low) give a residual volume of $0.93 \mu \mathrm{m}^{3} / \mathrm{m}^{3}$ for the SH and $0.3 \mu \mathrm{m}^{3} / \mathrm{m}^{3}$ for the $\mathrm{NH}$ at a normalized number density of $1 \mathrm{~cm}^{-3}$. However, from Fig. $4 \mathrm{~b}$ we see that we do not account for a significant fraction of volume. Therefore, we include residual particles up to $3 \mu \mathrm{m}$ in diameter in the volume determination, keeping in mind that the uncertainty is largest for super micron particles due to poor counting statistic. This increases the residual volume to $1.29 \mu \mathrm{m}^{3} / \mathrm{m}^{3}$ for the SH and to $0.4 \mu \mathrm{m}^{3} / \mathrm{m}^{3}$ for the $\mathrm{NH}$, the ratio of the calculated volume for the two hemispheres remains the same.

The reason for this bimodal structure is not known but clearly the residual particle volume is approximately three times larger in the $\mathrm{SH}$ - compared to the $\mathrm{NH}$ campaign.

\subsubsection{Residual number distributions grouped according to residual number density and temperature}

The campaign averages contain data sampled at vastly different conditions in terms of crystal number density, temperature and aerosol loading. Therefore we try to limit the influence of variability in these parameters by stratifying our data in different ranges. Ideally, we would like to study the residual aerosol after stratifying the data according to different atmospheric states (temperature and humidity), dynamical forcing (updraft and turbulence), aerosol loading (number density and composition) and finally microphysical properties (crystal number density and IWC). However, this is not

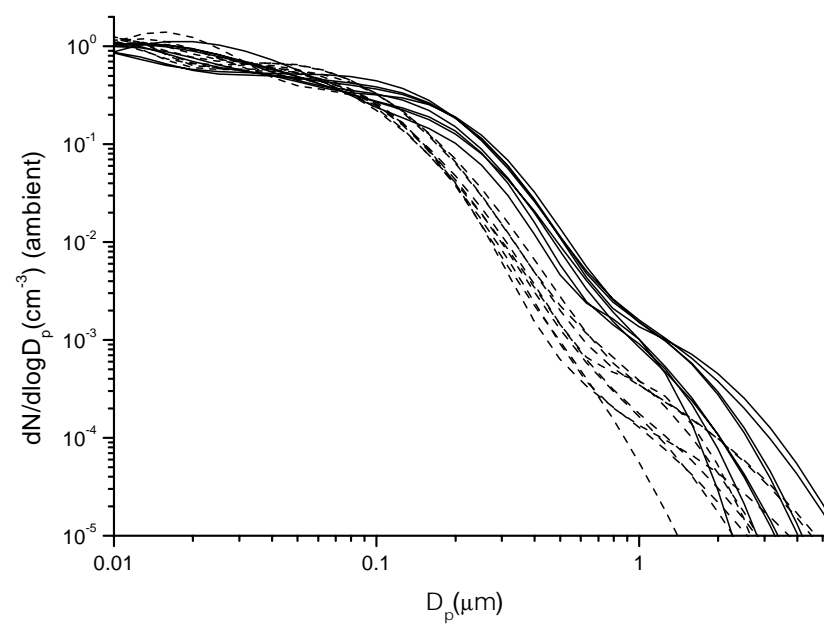

Fig. 5. Comparison of the residual number distributions for both campaigns grouped according to $\mathrm{N}_{\mathrm{CVI}, 10}$. For clarity only the data fits are presented. The data has been fitted by the sum of lognormal distributions such as the integral number of the resulting distribution would match the bin mean $\mathrm{N}_{\mathrm{CVI}}, 10$. The bin averages were $3,2.6$, $2.3,2.0,1.3,1,0.6$ and $0.3 \mathrm{~cm}^{-3}$. The data has been normalized to an integral number density of $1 \mathrm{~cm}^{-3}$. Solid lines refer to the $\mathrm{SH}$ and dashed lines to the $\mathrm{NH}$.

feasible, as our data set is extensive, but still finite. In order not to end up with insufficient statistic, we can take only one or two parameters at the time depending on the chosen interval widths.

First we analyze the residual number distribution as a function of the residual number density. The data was divided according to $\mathrm{N}_{\mathrm{CVI}} 10$ into 9 bins, where the average $\mathrm{N}_{\mathrm{CVI}, 10}$ was 3, 2.6, 2.3, 2.0, 1.6, 1.3, 1, 0.6 and $0.3 \mathrm{~cm}^{-3}$. To achieve a balance between the number of size distributions in each bin and the range in $\mathrm{N}_{\mathrm{CVI}, 10}$ of the bin, the bin limits were chosen such that each bin contained at least 20 size scans and the upper and lower bound of the $\mathrm{N}_{\mathrm{CVI}, 10}$ bin may not differed more than 20\%. Different interval limits were tried, but this approach gave the best balance between narrow bin width and acceptable statistical uncertainty. For the DMA data $\left(D_{p}=0.025-0.1 \mu \mathrm{m}\right)$ the uncertainty is below $1 \%$ in all $\mathrm{N}_{\mathrm{CVI}, 10}$ bins. In the PCASP size range the counting statistic error increases strongly with particle size. For particles between 0.1 and $1 \mu \mathrm{m}$ the uncertainty increases from $<1$ to $5 \%$ and 1 to $20 \%$ in the highest and lowest $\mathrm{N}_{\mathrm{CVI}, 10}$ range, respectively. For particles larger than $1 \mu \mathrm{m}$ the uncertainty is essentially a function of size. The uncertainty is increasing from 5 to $25 \%$ and 20 to $100 \%$, when changing the particle diameter from 1 to $3.5 \mu \mathrm{m}$ for the highest and lowest $\mathrm{N}_{\mathrm{CVI}, 10}$ range.

In order to compare the shape of the residual number distributions resulting from the different categories, we again normalize our distributions to $1 \mathrm{~cm}^{-3}$. This normalization was done since the mean residual number density ranges 


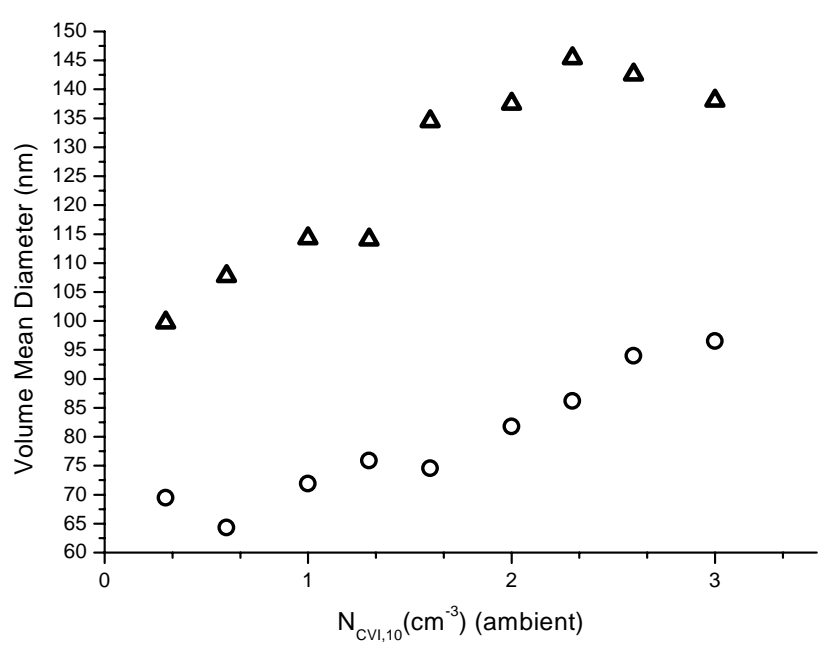

Fig. 6. Calculated volume mean diameter VMD as a function of $\mathrm{N}_{\mathrm{CVI}, 10}$. The diameters correspond to the $\mathrm{N}_{\mathrm{CVI}, 10}$ bins used in Fig. 5. Open circles is NH data and open triangles is $\mathrm{SH}$ data.

between 0.3 and $3 \mathrm{~cm}^{-3}$. The normalized distributions from both campaigns are presented in Fig. 5. Since we do not discuss features of the individual distributions, the data is presented as dashed lines for the $\mathrm{NH}$ and full lines for the $\mathrm{SH}$. For clarity and to declutter the graph only the fits to the average distributions are presented. Although the residual number density is varying over one order of magnitude, the shape of the residual number distributions changes very little within one hemisphere. The most evident difference between the two campaigns is the systematic difference between $\mathrm{SH}$ and NH distributions for diameters larger than $0.1 \mu \mathrm{m}$.

We have already shown that this feature is statistically significant for the campaign averages. To prove that this is also the case when comparing the two campaigns for the same $\mathrm{N}_{\mathrm{CVI}}$,10 range, we use once again a two-tailed t-test. In the size range 0.025 to $0.1 \mu \mathrm{m}$ the confidence level is varying between high values (>99\%) and low values (around 1\%) for different sizes in each bin. In the size range 0.1 to $1 \mu \mathrm{m}$ the confidence level is better than $99 \%$. For $\mathrm{D}_{\mathrm{p}}>1 \mu \mathrm{m}$ the confidence level is greater than $60 \%$, except for the distributions with integral values corresponding to 0.3 and $1.3 \mathrm{~cm}^{-3}$, where the confidence is greater than $30 \%$. Hence, the difference apparent in Fig. 5 is a statistically significant feature over a large part of the distribution. Due to this significant difference we keep the two data sets separated. If the data had been more similar one could have combined them to improve the statistic in subsequent analysis.

Although not evident in Fig. 5, there is an interesting trend in both hemispheres of an increasing fraction of accumulation mode particles with increasing residual number density.
Deriving the corresponding volume reveals that the residual volume per crystal is increasing with increasing $\mathrm{N}_{\mathrm{CVI}}, 10$. The observed trend may also be expressed in terms of residual VMD (volume mean diameter), which is given by $(6 / \pi$ total volume/total number of particles $)^{1 / 3}$. Figure 6 gives the relationship between residual number density and residual VMD. Changing the number density from 0.3 to $3 \mathrm{~cm}^{-3}$, causes the corresponding VMD to increase from 0.071 to $0.096 \mu \mathrm{m}$ and 0.100 to $0.139 \mu \mathrm{m}$ in the $\mathrm{NH}$ and $\mathrm{SH}$, respectively.

We know that temperature is very important for cirrus formation and evolution. It is of special interest to investigate the residual aerosol distributions that are present near the temperature associated with homogeneous freezing of supercooled liquid aerosol particles (around $235 \mathrm{~K}$ ). Each residual integral range contains size distribution measurements made at various temperatures, causing a mixing of data from different altitude levels. As we include a new parameter in our analysis we would like to stratify our data set further based on temperature. Ideally, we would like to keep the narrow $\mathrm{N}_{\mathrm{CVI}, 10}$ binning and compare cases for a given residual number density and temperature. However, this is not practical because this would result in insufficient amount of data in most bins. For this reason we proceed by grouping the data according to temperature in three regimes warm $(238 \mathrm{~K}<\mathrm{T}$ $<243 \mathrm{~K})$, intermediate $(235 \mathrm{~K}<\mathrm{T}<238 \mathrm{~K})$ and cold $(\mathrm{T}$ $<235 \mathrm{~K}$ ), and each regime is then divided into four residual number density ranges very high $\left(\mathrm{N}_{\mathrm{CVI}}, 103-10 \mathrm{~cm}^{-3}\right)$, high $\left(\mathrm{N}_{\mathrm{CVI}, 10} 1-3 \mathrm{~cm}^{-3}\right)$, intermediate $\left(\mathrm{N}_{\mathrm{CVI}}, 100.3-1 \mathrm{~cm}^{-3}\right)$ and low $\left(\mathrm{N}_{\mathrm{CVI}, 10} 0.1-0.3 \mathrm{~cm}^{-3}\right)$. Now, the freezing pathways are likely to be different in the three regimes. In the warm regime aerosols are activated into water droplets prior to freezing. Below $\mathrm{T}<235 \mathrm{~K}$ aerosol particles freeze before water saturation is reached. For intermediate temperatures both freezing paths take place. In addition the mode of nucleation may change between the three temperature regions. In the warm and intermediate temperature regime both heterogeneous and homogeneous freezing processes may occur, whereas for $\mathrm{T}$ $<235 \mathrm{~K}$ homogeneous freezing is believed to dominate ice nucleation. Assuming that only the homogeneous freezing mode is active during ice nucleation, the freezing probability is a strong function of size. For a given aerosol composition, solution droplets will nucleate starting from the large particle end of the aerosol size distribution. This results into a residual distribution where the number of residuals is dominated by accumulation mode particles, as observed for example for warm clouds (e.g. Glantz and Noone, 2002). However, no significant difference could be found between the size distributions based on different temperature intervals (Figure not provided). In fact comparing distributions between the different temperature ranges shows no significant statistical difference. This is a somewhat surprising finding given the expected importance of temperature in determining the mode of nucleation. 


\subsubsection{Scavenging ratios}

By comparing the residual size distributions, size distributions of the particles that became incorporated into the crystals, with those that remained non-activated as interstitial aerosol, we can study the fraction of a given aerosol size that participates in cloud formation.

Instead of dividing the $\mathrm{N}_{\mathrm{CVI}, 10}$ in further ranges we keep the four ranges (very high, high, intermediate, low) as described above. Except for three flights during the NH campaign the complete interstitial and residual size distributions are concurrent. From the SH campaign there is only a limited amount of data when all instruments (CPCs, DMAs and PCASPs) were working simultaneously. Most of the instrumental problems were related to the DMA originally assigned to the CVI probe. On some flights the DMA originally assigned to the interstitial inlet had to replace the CVIDMA. Hence, it was necessary to switch between the two inlets, which was simply done by a ball valve. With this operation we obtained size distribution measurements of the residual and interstitial particles in the DMA size range sequentially. It should be noted that during the ferry flights both DMAs were compared while measuring ambient aerosol in cloud free air, which proved the identical operation of the two DMAs.

The resulting interstitial and residual size distributions for the $\mathrm{SH}$ are presented in Fig. 7a. To guide the eye and in order to compare residual and interstitial distributions for a particular particle size, the data has been visually fitted using lognormal distributions.

With no correlation between the ambient aerosol and crystal number density, and with a sufficiently large data set, the average interstitial aerosol distribution should be indifferent for each $\mathrm{N}_{\mathrm{CVI}}, 10$ category. In other words, high crystal number densities should not necessarily be associated with high aerosol number densities or vice versa. This appears to be the case in the DMA size range for particles smaller than about $0.1 \mu \mathrm{m}$ in diameter, but not for the larger particle sizes. In the PCASP size range there is a clear correlation between the residual and interstitial particle number concentrations, where higher crystal number densities are associated with an increase in the number density measured by the wingmounted PCASP.

From the data in Fig. 7a we can derive the corresponding scavenging efficiency. The size-dependent scavenging ratio is defined as the ratio of residual particles to the total number of particles in each size bin. The total number of particles is given by the sum of the residual and interstitial particles.

In order to calculate the scavenging ratios we have made use of the fitted size distributions since the two PCASPs and CPCs have slightly different measurement size ranges and the bins do not correspond exactly with each other. The resulting scavenging ratios for the $\mathrm{SH}$ are presented in Fig. 8a. It is obvious that the overall ratio depends strongly on the total residual number density, but the correlation with larger
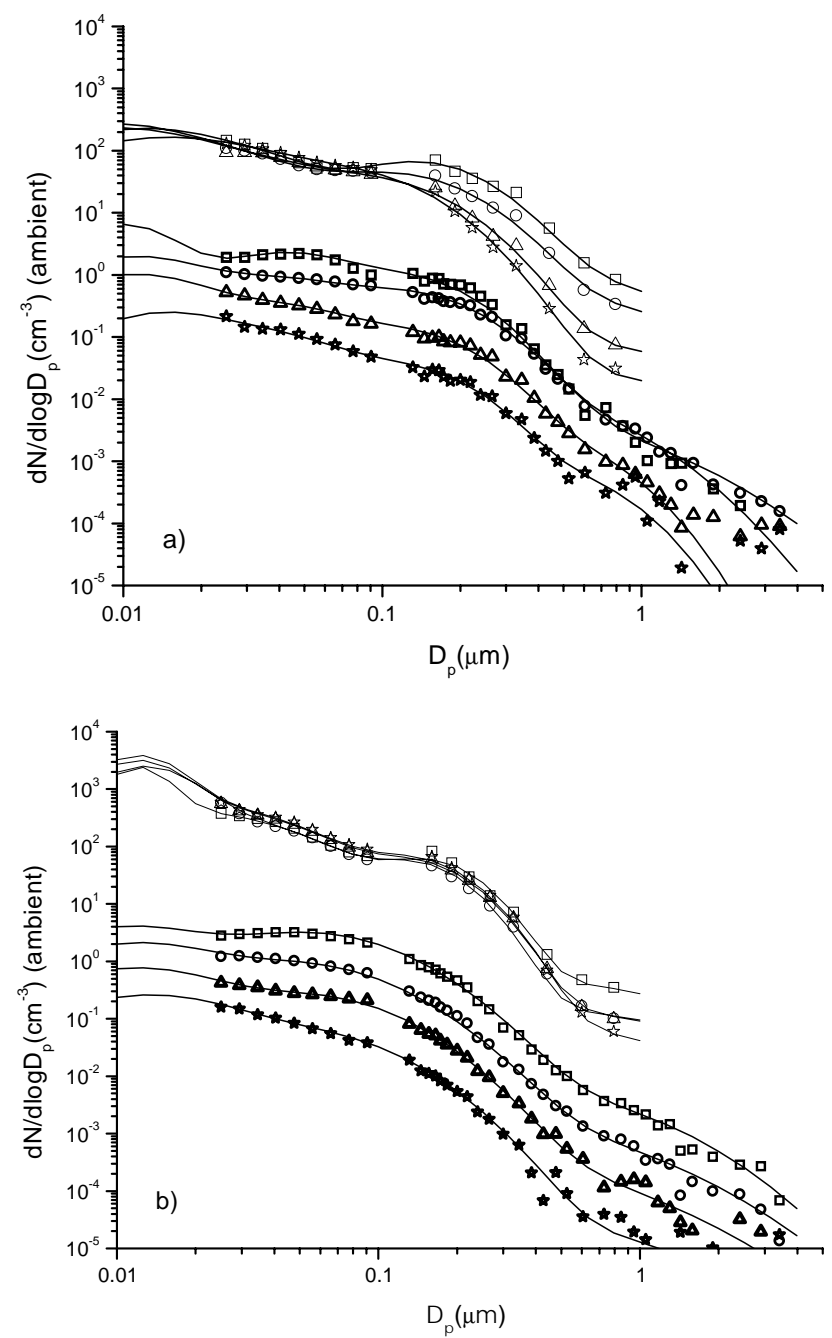

Fig. 7. Interstitial/residual number distribution corresponding to different $\mathrm{N}_{\mathrm{CVI}, 10}$ categories: very high $\left(\mathrm{N}_{\mathrm{CVI}}, 103-10 \mathrm{~cm}^{-3}\right)$, high $\left(\mathrm{N}_{\mathrm{CVI}, 10} 1-3 \mathrm{~cm}^{-3}\right)$, intermediate $\left(\mathrm{N}_{\mathrm{CVI}, 10} 0.3-1 \mathrm{~cm}^{-3}\right)$ and low $\left(\mathrm{N}_{\mathrm{CVI}, 10} 0.1-0.3 \mathrm{~cm}^{-3}\right)$. The data has been fitted by the sum of lognormal distributions such as the integral number of the resulting distribution would match the bin mean $\mathrm{N}_{\mathrm{CVI}, 10}$ for the residual distributions, respectively bin mean $\mathrm{N}_{\text {int, } 5}$ for the interstitial distributions. The interstitial data refers to open symbols: very high (squares), high (circles), intermediate (triangles) and low (stars). The residual data refers to thick symbols: very high (thick squares), high (thick circles), intermediate (thick triangles) and low (thick stars). The solid lines are the corresponding fits to the data. (a) data for the SH. (b) data for the NH.

interstitial particles makes the calculated ratios come closer together at larger sizes. Note that the scavenging ratio at sizes smaller than $0.025 \mu \mathrm{m}$ is estimated from the fitted curves. Nevertheless, the scavenging ratio is on the order of percent or less across the whole aerosol size range.

We now repeat the procedure in Fig. $7 \mathrm{~b}$ and $8 \mathrm{~b}$ for the NH-data. Figure $7 \mathrm{~b}$ shows the corresponding interstitial and 

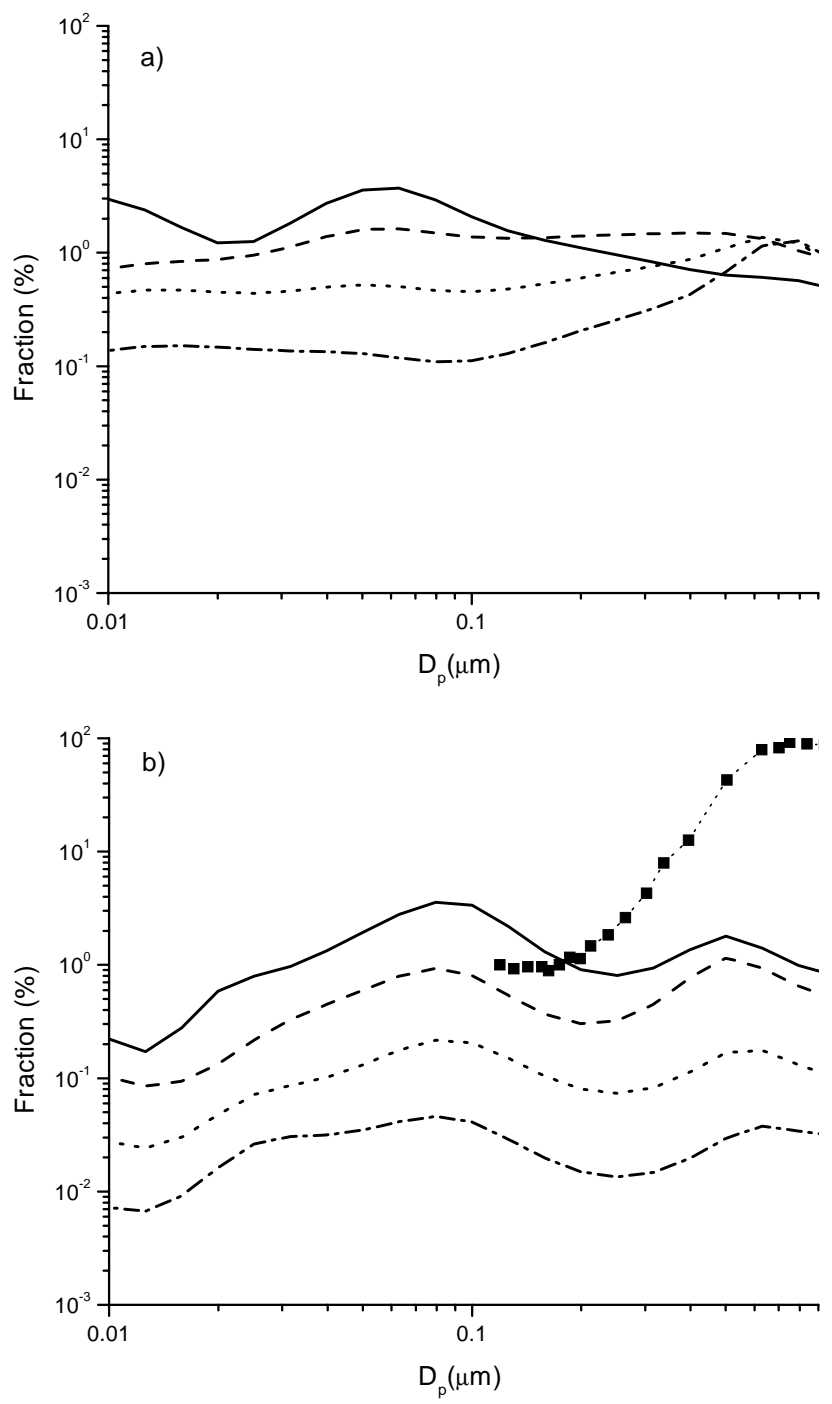

Fig. 8. Fraction of ambient particles included in the crystals as a function of particle size (fraction is only estimated below $D_{p}=$ $0.025 \mu \mathrm{m})$. The scavenging efficiency has been calculated from the fitted interstitial/residual distributions shown in Fig. 6 and correspond to different $\mathrm{N}_{\mathrm{CVI}, 10}$ categories: very high $\left(\mathrm{N}_{\mathrm{CVI}, 10}{ }_{3-}\right.$ $10 \mathrm{~cm}^{-3}$, solid line), high ( $\mathrm{N}_{\mathrm{CVI}}, 101-3 \mathrm{~cm}^{-3}$, dashed line), intermediate ( $\mathrm{N}_{\mathrm{CVI}, 10} 0.3-1 \mathrm{~cm}^{-3}$, dotted line), and low ( $\mathrm{N}_{\mathrm{CVI}, 10} 0.1-$ $0.3 \mathrm{~cm}^{-3}$, dash dotted line). (a) data for the $\mathrm{SH}$. (b) data for the $\mathrm{NH}$. The solid squares show a scavenging efficiency curve adapted by Ström et al. (1997) from a flight conducted over central Europe in 1994.

residual distributions for the $\mathrm{NH}$, and the scavenging ratios are presented in Fig. 8b. We first note that the average interstitial aerosol number density is by about a factor 6 higher in the NH compared to the SH in our data set. This is due to the enhanced Aitken and Nucleation mode particles in the NH. At interstitial particle sizes larger than about $0.1 \mu \mathrm{m}$ the two hemispheres are in average comparable with respect to number densities, but the variability is much stronger in the
$\mathrm{SH}$. This does not influence the total number density, but is significant in terms of total aerosol mass.

Although the average interstitial distributions are much closer together in the $\mathrm{NH}$, there is still a small tendency for a correlation between large interstitial aerosol and residual number density. In addition a closer look at the average interstitial size distributions shows that there is actually also a tendency of anti-correlation between the residual and interstitial particles for particles smaller than about $0.070-0.080$ $\mu \mathrm{m}$. However, the significance of that is questionable since the interstitial distributions are very close to each other in the measured size range. The lower variability in interstitial size distributions in Fig. 7b is also reflected in the scavenging ratios presented in Fig. 8b. Essentially, we see a strong proportionality between the different $\mathrm{N}_{\mathrm{CVI}} 10$ categories. As for the $\mathrm{SH}$, the ratio is small and usually less than a percent.

A first attempt to calculate this type of scavenging ratio was made by Ström et al. (1997). The derived scavenging efficiency from that study is also included in Fig. 8b. Clearly the present study and the study by Ström et al. (1997) deviate at particle sizes above a few hundred nanometers. The data in Ström et al. (1997) was obtained over Southern Germany during one flight in 1994. The same PCASP instrument (inside the aircraft) was used in both studies. The instrument was switched between the CVI and interstitial inlet during a flight leg and hence the ratio is derived from only a few minutes of data. As was pointed out in the beginning of this study the counting statistic is very poor for the accumulation mode particles if the sample time is too short. This is especially true for the interstitial particle sampling, since this inlet does not have the enrichment effect as the CVI inlet does.

In deriving the scavenging ratio the authors assumed a priori that all aerosol particles larger than around $1 \mu \mathrm{m}$ would be incorporated in cirrus crystals, which would be consistent with theoretical expectations. At residual particle sizes smaller than about $0.3 \mu \mathrm{m}$, where the counting statistic is much better, the two studies agree well. Hence, the explanation for the difference between the two studies may be the fact that our study includes several hundred times more size distribution data than in Ström et al. (1997). An interesting and perhaps very significant difference between the study by Ström et al. (1997) and the present study is that the flight in 1994 was conducted in a time period when central Europe was influenced by the plume from the volcano Pinatubo, Philippines. The ambient aerosol during these two studies was most likely significantly different.

\section{Discussion}

One may speculate that the presented size distributions of residuals are greatly different from those of the aerosol particles that actually have formed ice. Ramachandran and Reist (1995) have shown that fractal particles become more regular when they are subject to condensation followed 
by evaporation. When an aerosol composed of irregularly shaped agglomerates is incorporated into an ice crystal, the agglomerates are likely to undergo morphological changes once the crystal evaporates. The size of a particle after a condensation and evaporation cycle may therefore be significantly different. Aerosol particles are likely to undergo repeated cycles of condensation and evaporation and any collapse of fractal geometries is only expected for the first cycle. Furthermore we have to keep in mind that fractal particles, which are most likely of carbonaceous origin, only account for a subfraction of the total aerosol population in the upper troposphere. For these reasons the process of condensation and evaporation is not likely to significantly change the size distribution of the particles that formed ice crystals.

Another process that might modify the residual particles is scavenging of aerosol particles from the interstitial air. Once the ice crystals evaporate in the CVI scavenged interstitial particles may stick to the particle on which the crystal originated. In other words, the crystals interact with the interstitial aerosol that in turn influences the residual particles by making them larger. We may try to estimate the result of this potential process by assuming an ice crystal lifetime of 3 hours, a crystal diameter $D_{p 1}$ of $10 \mu \mathrm{m}$, and an interstitial diameter $D_{p 2}$ of $0.03 \mu \mathrm{m}$. The interstitial number density $N_{2}$ is $100 \mathrm{~cm}^{-3}$. The rate at which interstitial particles are transferred to one crystal is given by:

$d N / d t=K_{12} N_{2}\left(s^{-1}\right)$

The coagulation coefficient is defined as:

$K_{12}=2 \pi\left(D_{p 1}+D_{p 2}\right)\left(D_{1}+D_{2}\right)\left(s^{-1} \mathrm{~cm}^{3}\right)$

where $D_{1}$ and $D_{2}$ refer to the diffusion coefficients of the crystals and the aerosol, respectively. Whether scavenging affects the distribution depends very much on the size of the residual particles. Adjacent DMA bins differ in particle size by approximately $20 \%$. Given the conditions above, only residual particles smaller than about $0.03 \mu \mathrm{m}$ have a chance to grow that much. Thus we expect only a small or negligible effect on the smallest residual particles observed.

Our observations clearly show that the fraction of aerosol particles incorporated into cirrus crystals is very small for sizes ranging from tens of nanometers to several micrometers in diameter. It is also clear that the number densities of residual particles are controlled by particles smaller than $0.1 \mu \mathrm{m}$ in diameter, whereas the residual particle volume is controlled by particles larger than $0.1 \mu \mathrm{m}$ in diameter. Changes in atmospheric temperature do not seem to significantly affect the observed residual distributions.

Based on homogeneous nucleation theory this is an unexpected result (e.g. Heymsfield and Sabin, 1989; DeMott et al., 1994; Tabazadeh and Toon, 1998). At temperatures below the homogeneous freezing threshold the freezing probability is a strong function of size. For a given aerosol composition the scavenging fraction increases strongly with in- creasing aerosol size. This is why Jensen et al. (1994) argued that aerosol particles smaller than $0.6 \mu \mathrm{m}$ in diameter do not significantly affect ice nucleation in mid-latitudes. Homogeneous nucleation refers to the freezing of a solution droplet that has formed on a soluble cloud condensation nuclei $(\mathrm{CCN})$. Aerosol particles acting as $\mathrm{CCN}$ are believed to mainly consist of varying mixtures of $\mathrm{NH}_{3}, \mathrm{H}_{2} \mathrm{SO}_{4}$ and $\mathrm{H}_{2} \mathrm{O}$. Several model studies suggest that this mechanism is the dominating nucleation process (DeMott et al., 1994; Jensen and Toon, 1994; Tabazadeh and Toon, 1998). Theoretical studies have also demonstrated the sensitivity of homogeneous freezing to temperature. Therefore, we would have expected to see significant changes in the observed residual particles near the homogeneous freezing temperature (around $235 \mathrm{~K})$.

The observed scavenging ratios may be evidence for the potential importance of heterogeneous ice nucleation for cirrus formation. Heterogeneous nucleation refers to the freezing through direct deposition of water vapor on a heterogeneous ice nuclei (IN), or through the aid of a foreign particle stimulating freezing of super cooled haze droplets. Aerosol particles acting as IN, may consist of crustal, metallic, and carbonaceous material (Chen et al., 1998), but the shape, size may also play a role. The role of heterogeneous nucleation is still uncertain mainly due to the fact that composition and abundance of upper troposphere IN are not well known (Jensen and Toon, 1997; DeMott et al., 1998).

A problem with the heterogeneous mode of ice nucleation is that we have very little theory to compare our observations with. There are a number of process model simulations treating nucleation as a competitive process between homogeneous and heterogeneous freezing (e.g. DeMott et al., 1997). However Sassen and Benson (2000) show that heterogeneous nucleation cannot compete with homogeneous nucleation for most atmospheric situations. DeMott et al. (1994) concluded that changing size distribution and composition of aerosol particles may have large effects on the onset conditions of cirrus formations and the crystal number density. Several studies have pointed towards the contrary (Jensen et al., 1998; Krcher and Lohmann, 2001) suggesting that the aerosol properties have a very small impact on the cloud microphysics and that other factors are more important.

Our observations show quite clearly that the aerosol associated with the ice crystals is much smaller than expected from theory. Sampling problems such as crystal break-up can be dismissed on the basis of the cloud probe intercomparison presented in Gayet at al. (2002) and in this study. Recently the aerosol composition in the upper troposphere has shown to be very diverse (Murphy et al., 1998). The chemistry of ice nucleating aerosol particles might therefore be more complex than previously modeled and the size dependent state of the internal and external mixture of the aerosol has to be considered. 
The interstitial size distributions were very different during the two campaigns with a much larger population of small particles in the NH. The average residual size distributions were significantly different between the two campaigns as well, at least in the accumulation mode size range. However, the difference in the residual size distributions was smaller than the difference in interstitial aerosol. From the observations presented in this study we cannot determine what causes the shift towards large residual particles in the SH campaign, but we note that the $\mathrm{SH}$ mid-latitudes are mainly ocean, whereas the NH mid-latitudes have a much larger fraction of continents.

It is possible that the oceans of the $\mathrm{SH}$ are a greater source for large particles suitable for ice nucleation than the continents of the NH. Convection, which can introduce boundarylayer air to the upper troposphere, is believed to play a more important role in the NH. Hence in the NH the natural terragenic- and strong anthropogenic ground sources are likely to have a significant impact on the upper troposphere aerosol population. In addition particulates injected directly by aircraft are of regional importance, especially in the vicinity of the North Atlantic flight corridor.

The larger population of small ambient particles for the Prestwick campaign is consistent with the expected stronger influence of anthropogenic pollution in the Northern Hemisphere. However, more information about the chemical nature of the aerosol will be helpful in understanding the aerosol-cloud interaction of high clouds.

\section{Summary and Conclusions}

In-situ observations of the partitioning of aerosol particles in cold cirrus clouds have been presented. Cirrus observations were interpreted in the perspective of a potential influence by anthropogenic emissions on cirrus clouds. Several conclusions can be drawn from the results:

- The crystal residual distribution observed in the $\mathrm{SH}$ campaign and the $\mathrm{NH}$ campaign are significantly different. In the Southern Hemisphere the distribution is shifted towards larger sizes. This appears to have little effect on the total aerosol number density, but may have important implications in terms of vertical redistribution of aerosol volume or mass. In average three times as much aerosol volume is incorporated in cirrus clouds in the Southern Hemisphere for the same crystal number densities.

- The residual number density is controlled by particles smaller than $0.1 \mu \mathrm{m}$, whereas the residual volume distribution is controlled by particles larger than $0.1 \mu \mathrm{m}$. Obviously small aerosol particles must be included in any conceptual model of cirrus formation.

- The volume mean diameter is increasing with increasing residual number density within the temperature range $235-243 \mathrm{~K}$. Hence, when the crystal number density increases, the contribution of large residual particles increases.

- The shape of the residual size distributions is found to be insensitive to temperature variation.

- The data suggests a scavenging ratio in the order of one percent or less. The ratio is low for the whole aerosol size range, from a few tens of nanometers to several micrometers. Thus, the observations indicate that there is no strong preference for ice nucleation to occur on large aerosol particles to the extent expected for homogeneous nucleation. This suggests that size dependent aerosol chemistry might have to be considered in cirrus nucleation studies.

- The excellent agreement between the CVI and FSSP300 probes supports the assumption that each crystal is associated with only one residual particle.

Our current understanding of the cloud active aerosol is not sufficient to get a closure between observations and numerical simulations. The role of aerosol in nucleating cirrus cloud particles is highly uncertain. The results presented in this paper emphasize the need for further in-situ measurements focusing on questions dealing with chemistry of aerosol associated with cirrus formation.

Acknowledgements. We acknowledge the work by the flight department of DLR during the campaigns. Leif Bcklin and Nils Walberg were very helpful in the work with the instruments. We thank Brigitta Noone for solving all kinds of problems and Stefan Wilhelm for excellent support during the INCA preparation in Oberpfaffenhofen. This work was supported within the INCA project (contract EVK2-CT-1999-00039) by the European Commission.

\section{References}

Arnott, W. P., Dong, Y. Y., Hallet, J., and Poellot, M. R.: Role of small ice crystals in radiative properties of cirrus - A case study, FIRE-II, November 22, 1991, J. Geophys. Res., 99, 1371-1381, 1994.

Baker, M. B.: Cloud microphysics and climate, Science, 276, 10721078, 1997.

Baumgardner, D., Dye, J. E., Gandrud, B. W., and Knollenberg, R. G.: Interpretation of measurements made by the forward scattering spectrometer probe (FSSP-300) during the Airborne Arctic Stratospheric Expedition, J. Geophys. Res., 97, 8035-8046, 1992.

Borrmann, S., Luo, B. P., and Mishchenko, M.: Application of the T-matrix method to the measurement of aspherical (ellipsoidal) particles with forward scattering optical particle counters, J. Aerosol Sci., 31, 789-799, 2000.

Chen, Y. L., Kreidenweis, S. M., McInnes, L. M., Rogers, D. C., and DeMott, P. J.: Single particle analyses of ice nucleating aerosols in the upper troposphere and lower stratosphere, Geophys. Res. Lett., 25, 1391-1394, 1998. 
DeMott, P. J., Meyers, M. P., and Cotton, W. R.: Parameterization and impact of ice initiation processes relevant to numerical model simulations of cirrus clouds, J. Atmos. Sci., 51, 77-90, 1994.

DeMott, P. J., Rogers, D. C., and Kreidenweis, S. M.: The susceptibility of ice formation in upper tropospheric clouds to insoluble aerosol components, J. Geophys. Res., 102, 19575-19584, 1997.

DeMott, P. J., Rogers, D. C., Kreidenweis, S. M., Chen, Y. L., Twohy, C. H., Baumgardner, D., Heymsfield, A. J., and Chan, K. R.: The role of heterogeneous freezing nucleation in upper tropospheric clouds: Inferences from SUCCESS, Geophys. Res. Lett., 25, 1387-1390, 1998.

Gayet, J. F., Auriol, F., Minikin, A., Ström, J., Seifert, M., Krejci, R., Petzold, A., Febvre, G., and Schumann, U.: Quantitative measurement of the microphysical and optical properties of cirrus clouds with four different in situ probes: Evidence of small ice crystals, Geophys. Res. Lett., 29, 14 342-14 346, 2002.

Glantz, P., Noone, K. J., and Osborne, S. R.: Scavenging efficiencies of aerosol particles in marine stratocumulus and cumulus clouds, Q. J. R. Meteorol. Soc., 129, 1329-1350, 2003.

Heintzenberg, J., Okada, K., and Ström, J.: On the composition of non-volatile material in upper tropospheric aerosols and cirrus crystals, Atmos. Res., 41, 81-88, 1996.

Heymsfield, A. J. and Sabin, R. M.: Cirrus crystal nucleation by homogeneous freezing of solution droplets, J. Atmos. Sci., 46, 2252-2264, 1989.

Intergovernmental Panel on Climate Change (IPCC), 1999: Aviation and the Global Atmosphere, Penner, J. E., Lister, D. H., Griggs, D. J., Dokken, D. J., and McFarland, M. (Eds.), p.373, Cambridge Univ. Press, Cambridge, UK, 1999.

Jensen, E. J. and Toon, O. B.: Ice nucleation in the upper troposphere - sensitivity to aerosol number density, temperature, and cooling rate, Geophys. Res. Lett., 21, 2019-2022, 1994.

Jensen, E. J, Westphal, D. L., Kinne, S., and Heymsfield, A. J.: Microphysical modeling of cirrus 1 . Comparison with 1986 FIRE IFO measurements, J. Geophys. Res., 99, 10 421-10 442, 1994.

Jensen, E. J. and Toon, O. B.: The potential impact of soot particles from aircraft exhaust on cirrus clouds, Geophys. Res. Lett., 24, 249-252, 1997.

Jensen, E. J., Toon, O. B., Tabazadeh, A., Sachse, G. W., Anderson, B. E., Chan, K. R., Twohy, C. W., Gandrud, B., Aulenbach, S. M., Heymsfield, A., Hallett, J., and Gary, B.: Ice nucleation processes in upper tropospheric wave-clouds observed during SUCCESS, Geophys. Res. Lett., 25, 1363-1366, 1998.

Kärcher, B. and Lohmann, U.: A Parameterization of Cirrus Cloud Formation: Homogeneous Freezing Including Effects of Aerosol. J. Geophys. Res., 107, 10.1029/2001JD001429, 2002.
Murphy, D. M., Thomson, D. S., and Mahoney, T. M. J.: In situ measurements of organics, meteoritic material, mercury, and other elements in aerosols at 5 to 19 kilometers, Science, 282, 1664-1669, 1998.

Noone, K. B., Noone, K. J., Heintzenberg, J., Ström, J., and Ogren, J. A.: In-situ observations of cirrus cloud microphysical properties using the counterflow virtual impactor, J. Atmos. Oceanic Technol., 10, 294-303, 1993.

Noone, K. J., Ogren, J. A., Heintzenberg, J., Charlson, R. J., and Covert, D. S.: Design and Calibration of a Counterflow Virtual Impactor For Sampling of Atmospheric Fog and Cloud Droplets, Aerosol Sci. Technol., 8, 235-244, 1988.

Petzold, A., Dopelheuer, A., Brock, C. A., and Schröder, F.: In situ observations and model calculations of black carbon emission by aircraft at cruise altitude, J. Geophys. Res., 104, 22 171-22 181, 1999.

Ramachandran, G. and Reist, P. C.: Characterization of morphological changes in agglomerates subject to condensation and evaporation using multiple fractal dimensions, J. Aerosol. Sci., 23, 431-442, 1995.

Rogers, D. C., DeMott, P. J., Kreidenweis, S. M., and Chen, Y. L.: Measurements of ice nucleating aerosols during SUCCESS, Geophys. Res. Lett., 25, 1383-1386, 1998.

Sassen, K. and Benson, S.: Ice nucleation in cirrus clouds: A model study of the homogeneous and heterogeneous modes, Geophys. Res. Lett., 27, 521-524, 2000.

Schröder, F. and Ström, J.: Aircraft measurements of sub micrometer aerosol particles $(>7 \mathrm{~nm})$ in the midlatitude free troposphere and tropopause region, Atmospheric Research, 44, 333-356, 1997.

Ström, J., Heintzenberg, J., Noone, K. J., Noone, K. B., Orgen, J. A., Albers, F., and Quante, M.: Small crystals in cirriform clouds: A case study of residue size distribution, cloud water content and related cloud properties, Atmos. Res., 32, 125-141, 1994.

Ström, J., Strauss, B., Anderson, T., Schröder, F., Heintzenberg, J., and Wendling, P.: In situ observations of the microphysical properties of young cirrus clouds, J. Atmos. Sci., 54, 2542-2553, 1997.

Tabazadeh, A. and Toon, O. B.: The role of ammoniated aerosols in cirrus cloud nucleation, Geophys. Res. Lett., 25, 1379-1382, 1998.

Twohy, C. H. and Gandrud, B. W.: Electron microscope analysis of residual particles from aircraft contrails, Geophys. Res. Lett., 25, 1359-1362, 1998.

Zuber, A. and Witt, G.: Optical hygrometer using differential absorption of hydrogen Lyman-Alpha radiation, Appl. Opt., 26, 3083-3089, 1987. 